\title{
Selection of the appropriate method for the assessment of insulin resistance
}

\author{
Anwar Borai ${ }^{1,2^{*}}$, Callum Livingstone ${ }^{3,4}$, Ibrahim Kaddam ${ }^{1}$ and Gordon Ferns ${ }^{5}$
}

\begin{abstract}
Insulin resistance is one of the major aggravating factors for metabolic syndrome. There are many methods available for estimation of insulin resistance which range from complex techniques down to simple indices. For all methods of assessing insulin resistance it is essential that their validity and reliability is established before using them as investigations. The reference techniques of hyperinsulinaemic euglycaemic clamp and its alternative the frequently sampled intravenous glucose tolerance test are the most reliable methods available for estimating insulin resistance. However, many simple methods, from which indices can be derived, have been assessed and validated e.g. homeostasis model assessment (HOMA), quantitative insulin sensitivity check index (QUICKI). Given the increasing number of simple indices of $I R$ it may be difficult for clinicians and researchers to select the most appropriate index for their studies. This review therefore provides guidelines and advices which must be considered before proceeding with a study.
\end{abstract}

\section{Background}

An index of insulin resistance (IR) can be defined as a quantitative measurement of the biological effect of endogenous or exogenous insulin in relation to the ambient blood glucose level. IR is considered to be an independent risk factor for the development of metabolic syndrome and diabetes. Predisposition to IR is multi-factorial, with strong genetic and environmental influences. Over recent years there has been widespread scientific interest in this topic as it has become apparent that IR develops early in the pathological process leading to diabetes. Many studies have shown that it may predate the onset of the diabetes by 10-20 years [1]. Quantitative assessment of IR may therefore be useful for detecting its presence and assessing its severity, particularly in subjects who have not as yet developed abnormal glucose tolerance or diabetes. Although the presence of IR can be inferred from clinical findings it is not currently common practice to quantitate it in clinical contexts. Its quantitation is largely confined to research studies.

In a previous literature review [2] we classified methods of assessing IR into three main categories $v i z$ dynamic tests, simple indices and biochemical markers. In the

\footnotetext{
* Correspondence: boraiaa@ngha.med.sa

'Department of Pathology, King Khalid National Guard Hospital, Jeddah, Saudi Arabia

Full list of author information is available at the end of the article
}

dynamic tests such as the hyperinsulinaemic euglycaemic clamp (HEC) and its alternative technique the frequently sampled intravenous glucose tolerance (FSIVGTT) blood samples are collected serially. These are considered reference techniques. Relatively simple, non-invasive alternatives to the clamp technique have been proposed, such as homeostasis model assessment (HOMA). In addition it has been observed that measurement of individual biochemical protein markers such as insulin-like growth factor binding protein-1 (IGFBP-1) can provide useful information about the status of IR [3-5].

Previously studies have discussed the available methods for assessing IR including their applications and limitations [6,7] while other suggested some general requirements for an ideal method for measuring IR [8,9].

Faced with the wide array of indices available, it may be difficult for investigators to decide which is the most suitable for a particular purpose. However, no previous single publication has discussed the various factors that need to be considered in method selection. In this review we have collated available information on these factors in an effort to guide investigators in their choice of method.

\section{General considerations for choosing the appropriate technique prior quantitating insulin resistance} Investigators planning a study in which IR will be quantitated should in the first instance be clear about the
C Biomed Central

() 2011 Borai et al; licensee BioMed Central Ltd. This is an Open Access article distributed under the terms of the Creative Commons Attribution License (http://creativecommons.org/licenses/by/2.0), which permits unrestricted use, distribution, and reproduction in any medium, provided the original work is properly cited. 
type of study to be undertaken as this is the principle factor in determining the choice of method. The different types of study described in the literature and broad choice of method are summarised in Figure 1. The investigator should have prior knowledge of the available methods for assessing IR, their limitations and how to prepare subjects prior to investigation.

In making a decision, consideration should be given to the additional information required beyond the determination of IR. Some methods, particularly reference techniques, permit estimation of additional parameters of interest. Furthermore, some techniques provide an estimate of hepatic or peripheral IR or both. The investigator needs to consider whether the IR index is the primary endpoint of the study, such as would be the case in a study comparing IR between two populations, or of secondary interest. In selecting methodology there will be obvious logistical factors to consider. Below we consider in detail the different methods available for assessing IR and factors which investigators need to consider.

\section{Reference techniques}

The HEC should be the test of first choice in studies where IR is of primary interest [10]. It is a steady-state technique which requires a constant insulin infusion. Clearly this is unphysiological thus the HEC is not appropriate when an estimation of insulin action and glucose dynamics under normal physiological conditions is required.

Owing to the complexity of the HEC, the FSIVGTT may be preferred as an alternative option and, as such, can be considered the 'silver' standard [11]. The main FSIVGTT techniques available are the standard (classical) technique and the more modern insulin-modified version. Simplified short sampling protocols have been described for ease of studying large numbers of subjects [12]. Unlike the HEC, the FSIVGTT relies on dynamic glucose and insulin data obtained before and following an intravenous glucose bolus. It therefore measures IR indirectly. All FSIVGTT techniques require minimal model analysis in order to derive the insulin sensitivity index, $\mathrm{Si}$. This can only be done using software packages such as MINMOD. Many different software packages are available but do yield slightly different results. Investigators should endeavour to use the most modern version. In addition to determining $\mathrm{Si}$, the differential equations used by the MINMOD program can be utilised to estimate many other parameters of interest e.g.

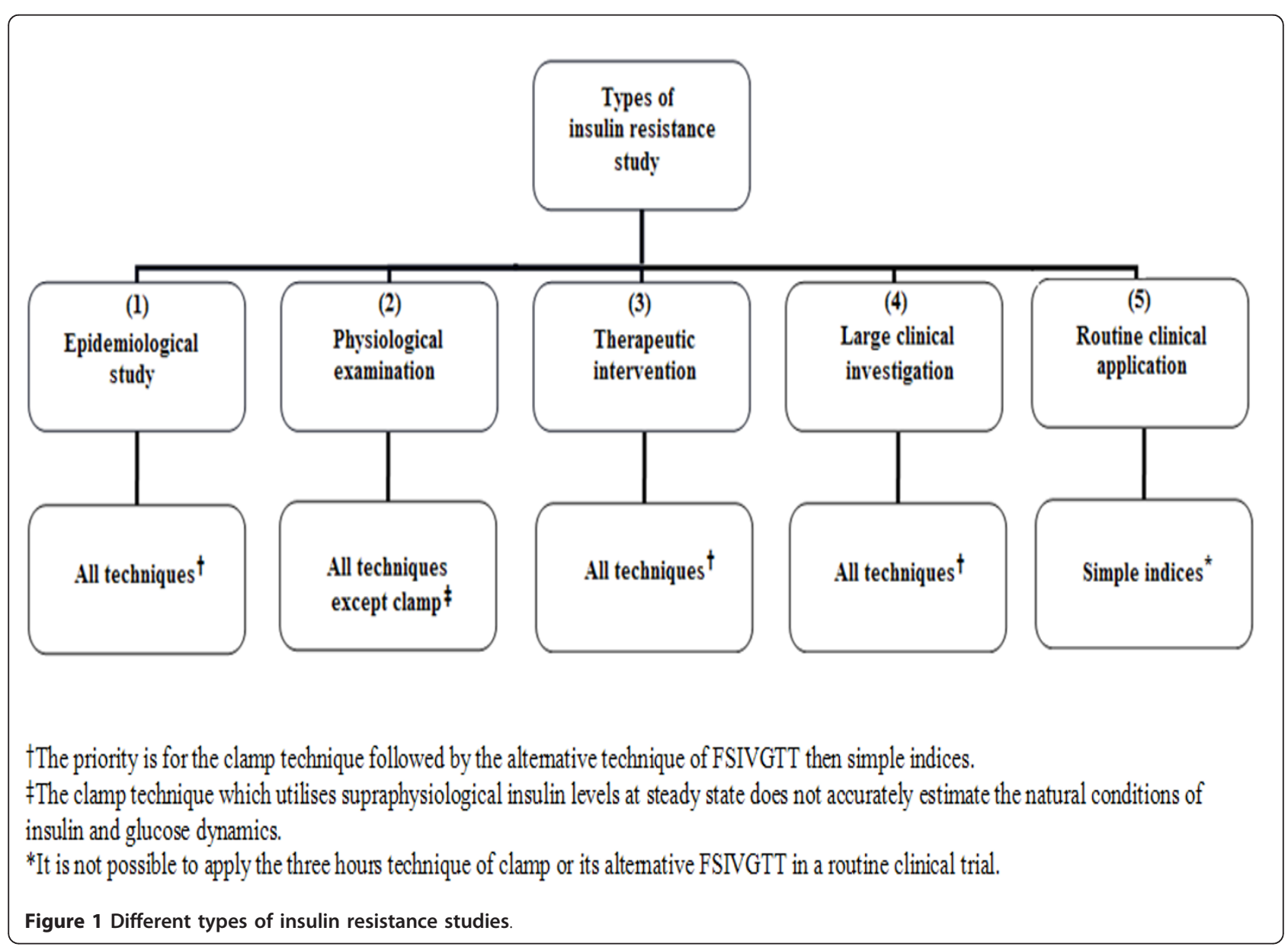


glucose effectiveness (Sg), $\beta$-cell activity ( $\beta$-cell), acute insulin response (AIR), disposition index (DI) and area under the curve (AUC). For investigators who are interested in these parameters the FSIVGTT will be the test of choice. However, it should be anticipated that for some subjects it may not possible to derive the various parameters from the available data. This is a common limitation of the technique encountered by authors, including ourselves, which should be taken into account when planning the number of study subjects to be recruited.

For investigators interested in assessing hepatic glucose production (HGP) and IR, stable isotopes of glucose can be used in combination with clamp or
FSIVGTT techniques. For further details on this topic readers are directed to an appropriate reference [13,14]. Other dynamic techniques such as the insulin tolerance test (ITT) and continuous infusion of glucose with model assessment (CIGMA) have not been widely benchmarked and only a few groups have used them in their studies [15-17]. We will not therefore discuss them further here.

\section{Number of subjects}

The number of subjects involved in a study is an important determinant of the feasibility of a given technique (Figure 2). It is well recognised that the reference techniques are generally unsuitable for epidemiological studies involving large numbers of subjects. However, there have

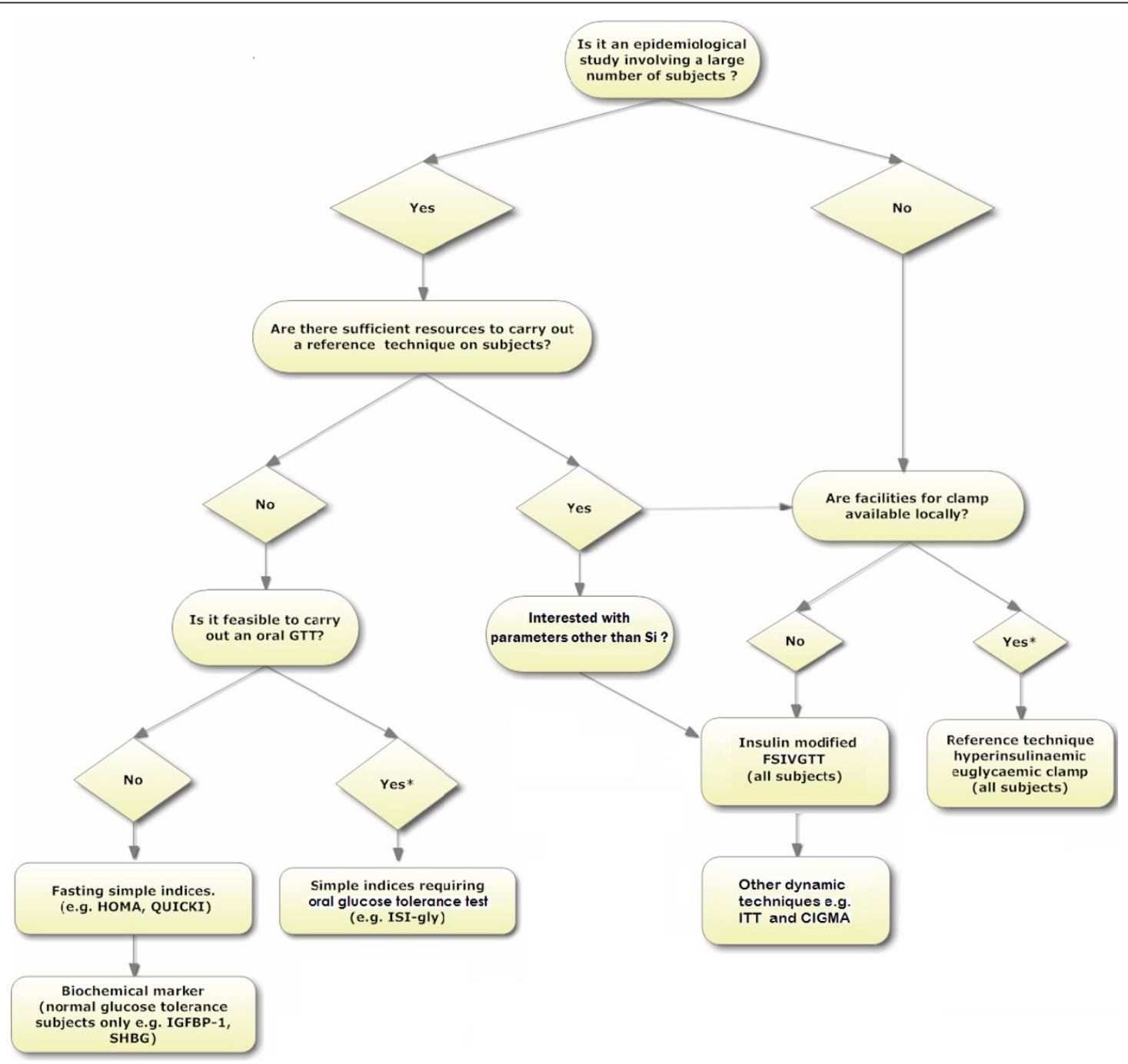

Figure 2 Protocol for selection the most appropriate technique for assessment of insulin resistance prior to commencement of a study.* This option is preferred. Key: FSIVGTT, frequently sampled intravenous glucose tolerance test; GTT, glucose tolerance test; HOMA, homeostasis model assessment; IGFBP-1, insulin-like growth factor binding protein-1; ISI-gly, insulin sensitivity index of glycaemia; ITT, insulin tolerance test; CIGM, continuous infusion of glucose with model assessment; QUICKI, quantitative insulin sensitivity check index; SHBG, sex hormone binding protein. 
been exceptions and, in principle, there is no reason why a reference technique should not be used in an epidemiological study provided sufficient resources are available. In the IR atherosclerosis study a large number of subjects $(\mathrm{n}=1,625)$ was used to examine the association between Si derived from insulin-modified FSIVGTT and other cardiovascular risk factors [18]. In general however, reference techniques have been confined to studies with relatively low numbers of subjects, especially when it is a pilot study investigating a new treatment modality or where a novel method is being validated [5,19].

\section{Glycaemic status of subjects}

Knowledge of the subjects' glycaemic status influences the choice of method. Where subjects with diabetes are to be studied, the HEC or insulin-modified FSIVGTT should be used. The classical FSIVGTT relies solely on the endogenous insulin response which, in diabetic subjects, may be insufficient to permit determination of Si. In addition, short protocol FSIVGTTs are best avoided in subjects with diabetes owing to poorer correlation of $\mathrm{Si}$ with the gold standard in these subjects. Clearly the glycaemic status of study subjects should be known by the investigator beforehand.

\section{Budget}

Budgetary constraints will clearly impact on the choice of the method. Where sufficient funds are available, the HEC reference technique is first choice but if this is not possible then the FSIVGTT would be recommended. However, it should be noted these methods cost 20-30 times more than the simple indices. Both the HEC and FSIVGTT require a dedicated member of staff with the necessary expertise. In the authors' experience it is desirable, in addition, to have a second member of staff available with expertise in the technique during attendance of study subjects, a factor worth considering in planning. Clearly this must be taken into account in budgetary considerations as staffing is likely to be the most significant contributor to the cost of the research.

\section{Materials and equipment}

The availability of appropriate technical expertise and materials must be considered if a reference technique is to be used. Essentially these techniques should be undertaken in a fully equipped clinical investigation unit in the presence of a suitably trained member of staff ( $e$. $g$. a nurse) able to manage any complications which may arise. A field study involving subjects who are unable to travel to the research centre would clearly preclude the use of a reference technique and demand use of simple technique on a single sample which could be processed and transported appropriately to the laboratory.

Experience with data analysis is another important factor to consider. If for example a software package such as MINMOD is to be used in conjunction with the FSIVGTT, for sophisticated data analysis, the operator should have the necessary skills for analysing the data and have access to support [20]. Both the HEC and FSIVGTT require cannulation of subjects, unlike the simple IR indices which only require straightforward venesection. The subjects' veins therefore need to be of sufficient quality if they are to be included and an operator must be present who possesses the necessary expertise.

\section{Previous studies}

Before utilising a reference technique in a study, it is advisable to share information with those with previous expertise in the technique so that potential difficulties and hazards, such as the risk of insulin-induced hypoglycaemia, can be identified. This will also enable the researcher to ascertain necessary details such as the protocol for use, possible application, pitfalls and limitations.

\section{Simple indices of insulin resistance}

A simple index of IR can be defined as an index which does not require the intravenous administration of exogenous insulin or glucose. It can be estimated either from a fasting specimen alone or fasting specimen along with other blood samples taken following an oral glucose load. Simple indices, unlike dynamic techniques, do not demand steady state conditions. Owing to their ease of application and convenience to subjects, simple indices are the most commonly used tools for estimating IR. Therefore, it is important to be aware whether a simple index of IR can or cannot be utilised in a given study. Criteria for use of simple indices of IR in a study are summarised in Table 1 . Whilst these are attractive in terms of their ease of use and inexpensive nature, investigators need to be aware of their limitations.

\section{Oral glucose tolerance test (GTT)-derived indices}

Mathematical formulae have been derived which represent the kinetics of insulin and glucose levels at different time intervals before and after administration of a $75 \mathrm{~g}$ oral glucose load during an oral glucose tolerance test (GTT). Several IR indices have been derived from two ( 0 and $120 \mathrm{~min}$ ) to four (0, 30, 60 and 120 minutes) samples of insulin and glucose taken in the context of a GTT (Table 2). More GTT-derived indices have been described which are summarised by Monzillo et al., [7] and Matsuda et al., [21]. Most but not all studies indicate that these indices are more reliable than other simple fasting indices of IR as their correlation with reference techniques was stronger than that of fasting indices [4,9,21-24]. This is to be expected as GTTderived indices take post-load glucose-insulin interaction into account. Whenever the dynamic techniques cannot be utilised in a study, simple GTT-derived indices should therefore be next in line for quantitation of IR. 
Table 1 Criteria for studies in which simple indices of insulin resistance may be used.

\begin{tabular}{ll}
\hline 1. & Study objectives \\
2. & Large clinical practice and epidemiological investigations [70]. \\
3. & Where the assessment of direct IR is not required. \\
4. & Where the outcome of IR is of secondary interest [71]. \\
5. & Where the requirements of reference techniques are not available e.g equipments, trained staff, enough budget. \\
6. & Investigating validity and pitfalls of simple indices in specific clinical conditions [41,57]. \\
\hline
\end{tabular}

References have been provided as a study example:

\section{Physiological response}

A criticism of the gold standard test is that the indices derived are not measured under physiological circumstances. When the investigator wishes to use an index that reflects the physiological insulin response to a glucose load then it is appropriate to use one derived from parameters measured during a GTT. These surrogate indices are derived from a dynamic response which generally incorporates both peripheral and hepatic IR. An advantage of the GTT-derived indices over those derived from fasting insulin and glucose alone is that they can detect subtle disturbances in glucose metabolism not apparent from the latter $[25,26]$. Simple indices based solely on fasting measurements cannot always reliably estimate IR, since it is possible for subjects to be significantly insulin resistant without having fasting hyperinsulinaemia. Furthermore, some individuals may be euglycaemic when fasting but hyperglycaemic and hyperinsulinaemic two hours following a $75 \mathrm{~g}$ oral glucose load. It is recognised that even in healthy individuals with hepatic IR, regular diet, exercise or glucose lowering medications can restore both fasting glucose and insulin levels to well within normal ranges $[27,28]$. In the authors' experience, the larger the number of specimens collected from an individual, the more accurately the derived parameters are likely to reflect insulin sensitivity [29]. This is because the biological variation of insulin and glucose levels has less impact on the value of the parameter when it is derived from a larger quantity of data.

It is noteworthy that the early glucose response during a GTT can be considered an index of hepatic IR, while the drop in glucose levels from peak to nadir estimates peripheral IR predominantly of skeletal muscle with a smaller contribution from adipose tissue [30]. A potential limitation of the GTT is poor reproducibility [31]. This arises from intra-individual variation in glucose handling both pre- and post-absorption. This problem can be reduced by repetition of the test on two or three occasions at short intervals and taking the mean of the results, if the investigator considers this feasible.

\section{Fasting sample-derived indices}

IR indices can be derived from fasting samples using mathematical formulae representing the kinetics of fasting insulin with or without glucose measurement (Table 2 ). These are the most commonly used indices of IR. The reasons for this wide application are their simplicity, cost-effectiveness and practicality as only one fasting sample is required and there is no requirement for

Table 2 Formulae for the most commonly used simple indices of insulin resistance derived from fasting specimens and other specimens taken in the context of an oral glucose tolerance test (GTT).

\begin{tabular}{lll}
\hline Index & Formula & Reference \\
\hline GTT derived indices: & & \\
ISI-gly & $2 /[(\mathrm{INS} p \times \mathrm{GLY})]+1$ & {$[74]$} \\
ISI (composite) & $1000 / \sqrt{ }\{[$ fasting glucose $(\mathrm{mg} / \mathrm{dL}) \times$ fasting insulin $(\mu \mathrm{U} / \mathrm{mL})] \times[$ mean glucose $\times$ mean insulin]\} & {$[21]$} \\
Fasting sample indices: & & {$[36]$} \\
HOMA-IR & Fasting glucose $(\mathrm{mmol} / \mathrm{L}) \times$ fasting insulin $(\mathrm{mU} / \mathrm{L}) / 22.5$ & {$[37]$} \\
HOMA2-S & HOMA2 calculator version 2.2 & {$[58]$} \\
FGIR & Fasting glucose $(\mathrm{mg} / \mathrm{dL}) /$ Fasting insulin $(\mathrm{mU} / \mathrm{L})$ & {$[33]$} \\
Raynaud & $40 /$ Fasting insulin $(\mathrm{mU} / \mathrm{L})$ & {$[34]$} \\
Reciprocal insulin & $1 /$ fasting insulin $(\mathrm{mU} / \mathrm{L})$ & {$[46]$} \\
QUICKI & $1 /[$ log fasting insulin $(\mathrm{mU} / \mathrm{L})+$ log fasting glucose $(\mathrm{mg} / \mathrm{dL})]$ & {$[58]$} \\
FGIR & Fasting glucose $(\mathrm{mg} / \mathrm{dL}) /$ Fasting insulin $(\mathrm{mU} / \mathrm{L})$ & \\
\hline
\end{tabular}

Key: GTT, oral glucose tolerance test; HOMA-IR, homeostasis model assessment insulin resistance; QUICKI, quantitative insulin sensitivity check index; FGIR, fasting glucose insulin ratio; ISI (composite), an index of whole-body insulin sensitivity; ISI-gly, insulin sensitivity glycemic index; INSp, insulinemic area; GLYp, glycemic area. 
administration of a glucose load. The main problems for the investigator are understanding the information that each index provides and choosing one from the large number available. The investigator should be mindful of the fact that these indices vary widely in their reliability [32]. Not all have been rigorously validated against the gold standard. The following points therefore need to be considered before selecting any fasting sample-derived index.

\section{Parameters involved in the formula}

Many of the formulae for indices derived from fasting specimens are simple using the fasting insulin level alone. An example of this is the Raynaud index which describes the best-fit relationship between fasting insulin and Si [33]. Another simple index is the reciprocal of the fasting insulin level (1/insulin) [34]. In spite of the modification of the original data by such formulae, these indices still rely solely on the insulin level and consequently suffer from the same limitations as the fasting insulin level alone [2]. Formulae which incorporate at least the two main parameters viz insulin and glucose, are preferable over those utilising insulin alone. Such formulae represent the exchangeable kinetics between both parameters which ultimately estimate IR. Other formulae have been reported which incorporate more than two parameters for example the lipid-parameter based formula [35]:

Lipid-based index $=12 \times[2.5 \times(\mathrm{HDL}-\mathrm{C} /$ Total cholesterol $)-\mathrm{NEFA}]-$ Fasting insulin

(HDL-C, high density lipoprotein cholesterol; NEFA, non-esterified fatty acids)

Indices which incorporate more than one parameter have high validity in predicting IR as demonstrated by their close association with reference test-derived indices of IR.

\section{Upgraded and modified formulae}

Simple IR indices have undergone regular modification by researchers in an effort to improve their applicability. Upgraded formulae have been observed to be more closely associated with reference test-derived indices and consequently more reliable and accurate. For example, the original HOMA equation (HOMA-IR) has been modified to HOMA2 to allow for increased plasma insulin and glucose levels [36,37].

Another means by which equations have been upgraded is incorporating additional parameters into their formulae. For example the fasting non-esterified fatty acid (NEFA) concentration when incorporated into the regular formula of QUICKI (quantitative insulin sensitivity check index) improves the estimation of IR as the modification enhances its correlation with the clamp-based index of insulin sensitivity and its discriminatory power $[38,39]$. Another example is the use of fasting C-peptide as a substitute for insulin in determining HOMA-IR which can be applied to subjects with insulin-treated diabetes [40]. Researchers using a simple index of IR are advised to use the most up-to-date version in order to obtain the strongest correlation with reference methods.

\section{Mathematical considerations}

Due to the simple mathematical nature of some fasting sample-derived indices, there is the potential for their output to be misinterpreted in some subjects particularly in those with type 2 diabetes where their levels may be paradoxically and erroneously increased e.g. fasting glucose to insulin ratio (FGIR), 1 /fasting insulin. This is due to low insulin secretion by pancreatic $\beta$-cells [41].

One feature of both the simple and reference methodderived indices of IR is that their values tend to be positively skewed yielding a hyperbolic curve when nontransformed data is examined. They become normally distributed following log-transformation. Previous studies have shown an improvement in their correlation with the reference techniques after log-transformation [4,42-45]. The QUICKI index for example is similar to HOMA, except that it interprets the data by taking both logarithms and the reciprocal of the fasting glucoseinsulin product. The log-transformation included in the formula of QUICKI results in greater accuracy than HOMA in calculations over a broad range of insulin sensitivity and in stronger correlation with the HEC $(\mathrm{r}=$ $0.78, \mathrm{p}<2 \times 10^{-12}$ ) $[46,47]$. Similarly, log or ln transformation of all simple indices of IR results in a stronger association with reference techniques and consequently an improvement in IR estimation. However, the degree of improvement reported varies between indices $[4,46]$.

\section{Biological variation}

Recent studies have indicated that the biological variation of insulin levels and fasting sample-derived indices of IR are greatly influenced by the degree of glucose tolerance and also by IR-modifying medications [48-50]. Owing to biological variation in fasting insulin levels, values for fasting sample-derived indices are more reliable in subjects with normal glucose tolerance than in individuals with type 2 diabetes. These factors should be borne in mind by researchers carrying out studies which involve repetition of levels at various time intervals. It may be advisable to confirm the glycaemic status by means of a GTT particularly if a long time interval is involved such as during a prospective study, as the glycaemic status may change over the course of the study. Researchers should also be aware that the values for indices which utilise multiple parameters will reflect the biological and analytical variation of each individual parameter. The result obtained for any index is only as good as the data entered. 


\section{Multiple simple indices}

Where there is uncertainty as to which simple index is most suitable in a study, more than one can be used simultaneously e.g. HOMA-IR, QUICKI, etc. This may help to minimise the effect of limitations of some indices and increase the likelihood of obtaining meaningful differences between categories of subjects under investigation $[26,42,51]$. In the authors' experience, the results of different simple indices are not always in line with each other. It is therefore wise to use more than one index in a given study in order to avoid reaching erroneous conclusions.

\section{Insulin assay}

The nature of the insulin assay to be used must be taken into consideration before commencing any study of IR, not only for those using simple indices. Currently all insulin assays are standardised using the same reference preparation but values obtained using different insulin assay kits may show significant bias. This may be due to variable specificity, different calibration set-up in kits or different factors used to convert between units (from $\mathrm{mIU} / \mathrm{L}$ to $\mathrm{pmol} / \mathrm{L}$ ) which vary from 6.0 to 7.46 [52]. Insulin represents the main parameter involved in the estimation of any simple index estimation. Manley et al., found that the distribution of HOMA2-IR estimates for different insulin assay (11 assays) varied by up to twofold, depending on which insulin assay was used [53]. Bias in results obtained by different insulin assays may contribute to the differences in reported cut-off values for IR in different populations [54,55]. In view of the above, it is highly advisable that, in any given study, one source of insulin assay is used throughout which has high performance criteria (i.e. company, antibodies). In addition, the same lot number of the assay products should be used if possible. This is particularly important in large prospective studies.

\section{Limitations of simple indices}

Indices derived from fasting samples can be unreliable when applied to certain groups of subjects viz the elderly and those with uncontrolled diabetes or type 1 diabetes $[46,56,57]$. The measured insulin level will not accurately reflect the degree of IR in these individuals as the $\beta$-cells are unable to secrete sufficient insulin to overcome existing IR. Indices derived from fasting samples are therefore more reliable when applied to individuals with sufficient insulin secretion. For example FGIR has been observed to be reliable in subjects with polycystic ovary syndrome (PCOS) except those who also have type 2 diabetes $[41,58]$. As is the case with the reference techniques, it is therefore advisable, when using simple indices, that the subject's glycaemic status is classified beforehand by means of a GTT and WHO criteria, even where post-load values are not required for determination of the index itself.
Simple indices based on fasting levels of glucose and insulin (e.g. HOMA-IR and QUICKI) assess hepatic IR more than peripheral insulin sensitivity. This has been demonstrated by the strong relationship observed between simple indices and the reference parameter of hepatic IR obtained by Hoffman et al., utilising FSIVGTT technique [59]. Hepatic IR is considered the major determinant of fasting hyperglycaemia and as such is the major factor contributing to the pre-diabetic state, impaired fasting glucose $[18,19]$. In most circumstances peripheral tissue IR develops later than hepatic IR [19]. This is an important limitation of fasting simple indices. Whilst hepatic and peripheral IR correlate with each other the relative contribution of each varies between individuals.

\section{Biochemical markers of IR}

The concentration of a given protein obtained from a fasting blood sample is potentially a more convenient means of assessing IR than measuring glucose and insulin together. Many possible biochemical markers were discussed in our previous review [2].

\section{Degree of insulin resistance}

Other than the fasting insulin level itself, initial studies have indicated that proteins which are either directly or indirectly insulin-regulated are more reliable as markers of IR than insulin independent protein markers $[3,5,60,61]$. In individuals with normal glucose tolerance the application of these biochemical markers is very reliable and convenient as they have been observed to be highly associated with IR parameters determined by reference techniques. However, they have been noted to be less-reliable in subjects with more marked degrees of IR resulting in an abnormal glucose tolerance $[4,5,62]$. This observation may be due to the presence of hepatic IR and consequently irregular secretion of these markers by hepatocytes as liver is considered to be the main source of most of these biochemical markers.

\section{Ratio between different markers}

The ratio of biochemical markers other than insulin and glucose may be another option for a simple and efficient marker of IR. For example, the ratios of leptin to adiponectin or between triglycerides and high density lipoprotein cholesterol can be considered useful markers of IR [63-65]. Low triglyceride levels are usually associated with increased insulin sensitivity but it appears that the relationship between triglycerides and insulin sensitivity differs between races, African-Americans for example having lower triglyceride levels in spite of increased insulin resistance [66]. Therefore, as with all biochemical markers, the results of these indices should not be interpreted in isolation but in the context of other findings including anthropometric measurements such as body mass index (BMI) and waist circumference and 
biochemical measurements. Age, gender, race etc. should be considered also.

\section{Biological variation for different markers}

The issue of biological variation as discussed above in relation to fasting indices, also applies to single biochemical markers of IR. Jaygobal et al., previously investigated the biological variation of sex hormone binding globulin (SHBG) as a biochemical marker of IR [67] and found that a second level must rise or fall by $>14.5 \%$ to be considered significantly different from the first in subjects with type 2 diabetes. Similarly, we assessed the biological variation of serum IGFBP-1 in individuals with different degrees of glucose tolerance [68]. Our study showed that biological variation of IGFBP-1 is lowest in normal glucose tolerant individuals and increased with deteriorating glucose tolerance. Therefore, biological variation should be considered whenever biochemical markers, influenced directly or indirectly by insulin, are utilised to assess IR. Generally, biological variation for most of the analytes and proteins including other biochemical markers can be retrieved from the database using the following website (http://www.westgard.com/biodatabase1.htm) [69].

\section{Conclusions}

A wide variety of methods are available for assessing IR including reference techniques and simple indices. In planning studies on IR and selecting a suitable index, a number of important factors need to be considered by investigators, the principle one being the nature of the study to be undertaken. Where possible the HEC, as the most accurate technique available, remains the first choice but simpler and inexpensive methods may be appropriate provided the investigator is aware of their limitations.

\section{List of abbreviations}

AIR: acute insulin response; AUC: area under the curve; CIGMA: continuous infusion of glucose with model assessment; DI: disposition index; FSIVGTT: frequently sampled intravenous glucose tolerance; FGIR: fasting glucose insulin ratio; GTT: glucose tolerance test; HEC: hyperinsulinaemic euglycaemic clamp; HOMA: homeostasis model assessment; HGP: hepatic glucose production; IR: insulin resistance; ISI-(gly): insulin sensitivity glycaemia index; IT: insulin tolerance test; Sg: glucose effectiveness; NEFA: fasting non-esterified fatty acid; QUICKI: quantitative insulin sensitivity check index; \% $\beta$-cell: $\beta$-cell activity

\section{Acknowledgements}

The authors acknowledge the unlimited support received from King Abdullah International Medical Research Center (KAIMRC) of the National Guard Health Affairs, Saudi Arabia.

\section{Author details}

'Department of Pathology, King Khalid National Guard Hospital, Jeddah, Saudi Arabia. ${ }^{2}$ King Abdullah International Medical Research Center-Jeddah, Saudi Arabia. ${ }^{3}$ Faculty of Health \& Medical Sciences, University of Surrey, UK. ${ }^{4}$ Clinical Biochemistry Department, Royal Surrey County Hospital, Guildford, UK. ${ }^{5}$ Institute for Science and Technology in Medicine, University of Keele, UK.

\section{Authors' contributions}

The work presented here was carried out in collaboration between all authors. All authors read and approved the final manuscript. The individual contributions of authors to the manuscript are as follow - AB: the main author who wrote the paper, designed the main theme, titles and subtitles. It was his idea to write the article. CL: co-designer for the main titles and subtitles, filled the gaps between lines and main manuscript, English Language Check. IK: the article's main reviewer, provided additional references and comments. GF: final revision before submission, added many comments and suggestions, English Language Check.

\section{Competing interests}

The authors declare that they have no competing interests.

Received: 23 June 2011 Accepted: 23 November 2011

Published: 23 November 2011

\section{References}

1. Lillioja S, Mott DM, Howard BV, Bennett PH, Yki-Jarvinen H, Freymond D, Nyomba BL, Zurlo F, Swinburn B, Bogardus C: Impaired glucose tolerance as a disorder of insulin action. Longitudinal and cross-sectional studies in Pima Indians. N Engl J Med 1988, 318(19):1217-1225.

2. Borai A, Livingstone $C$, Ferns $G$ : The biochemical assessment of insulin resistance. Ann Clin Biochem 2007, 44:324-342

3. Birkeland Kl, Hanssen KF, Torjesen PA, Vaaler S: Level of sex hormonebinding globulin is positively correlated with insulin sensitivity in men with type 2 diabetes. J Clin Endocrinol Metab 1993, 76(2):275-278.

4. Borai A, Livingstone $\mathrm{C}$, Zarif $\mathrm{H}$, Ferns $\mathrm{G}$ : Serum insulin-like growth factor binding protein-1: an improvement over other simple indices of insulin sensitivity in the assessment of subjects with normal glucose tolerance. Ann Clin Biochem 2009, 46(Pt 2):109-113.

5. Maddux BA, Chan A, Mandarino LJ, Goldfine ID: IGF-binding protein-1 levels are related to insulin-mediated glucose disposal and are a potential serum marker of insulin resistance. Diabetes Care 2006, 29(7):1535-1537.

6. Wallace TM, Matthews DR: The assessment of insulin resistance in man. Diabet Med 2002, 19(7):527-534

7. Monzillo LU, Hamdy O: Evaluation of insulin sensitivity in clinical practice and in research settings. Nutr Rev 2003, 61(12):397-412.

8. Groop LC, Widen E, Ferrannini E: Insulin resistance and insulin deficiency in the pathogenesis of type 2 (non-insulin-dependent) diabetes mellitus: errors of metabolism or of methods? Diabetologia 1993, 36(12):1326-1331.

9. Antuna-Puente B, Disse E, Rabasa-Lhoret R, Laville M, Capeau J, Bastard JP: How can we measure insulin sensitivity/resistance? Diabetes Metab 2011, 37(3):179-188.

10. DeFronzo RA, Tobin JD, Andres R: Glucose clamp technique: a method for quantifying insulin secretion and resistance. Am J Physiol 1979, 237(3): E214-223.

11. Bergman RN, Ider $Y Z$, Bowden CR, Cobelli C: Quantitative estimation of insulin sensitivity. Am J Physio/ 1979, 236(6):E667-677.

12. Saad MF, Anderson RL, Laws A, Watanabe RM, Kades WW, Chen YD, Sands RE, Pei D, Savage PJ, Bergman RN: A comparison between the minimal model and the glucose clamp in the assessment of insulin sensitivity across the spectrum of glucose tolerance. Insulin Resistance Atherosclerosis Study. Diabetes 1994, 43(9):1114-1121.

13. Caumo A, Giacca A, Morgese M, Pozza G, Micossi P, Cobelli C: Minimal models of glucose disappearance: lessons from the labelled IVGTT. Diabet Med 1991, 8(9):822-832.

14. Choukem SP, Gautier JF: How to measure hepatic insulin resistance? Diabetes Metab 2008, 34(6 Pt 2):664-673.

15. Shen SW, Reaven GM, Farquhar JW: Comparison of impedance to insulinmediated glucose uptake in normal subjects and in subjects with latent diabetes. J Clin Invest 1970, 49(12):2151-2160.

16. Bonora E, Moghetti P, Zancanaro C, Cigolini M, Querena M, Cacciatori V, Corgnati A, Muggeo M: Estimates of in vivo insulin action in man: comparison of insulin tolerance tests with euglycemic and hyperglycemic glucose clamp studies. J Clin Endocrinol Metab 1989, 68(2):374-378.

17. Hosker JP, Matthews DR, Rudenski AS, Burnett MA, Darling P, Bown EG, Turner RC: Continuous infusion of glucose with model assessment: 
measurement of insulin resistance and beta-cell function in man Diabetologia 1985, 28(7):401-411.

18. Howard G, O'Leary DH, Zaccaro D, Haffner S, Rewers M, Hamman R, Selby JV, Saad MF, Savage P, Bergman R: Insulin sensitivity and atherosclerosis. The Insulin Resistance Atherosclerosis Study (IRAS) Investigators. Circulation 1996, 93(10):1809-1817.

19. Sanyal AJ, Mofrad PS, Contos MJ, Sargeant C, Luketic VA, Sterling RK, Stravitz RT, Shiffman ML, Clore J, Mills AS: A pilot study of vitamin E versus vitamin $\mathrm{E}$ and pioglitazone for the treatment of nonalcoholic steatohepatitis. Clin Gastroenterol Hepatol 2004, 2(12):1107-1115.

20. Bergman RN: Lilly lecture 1989 . Toward physiological understanding of glucose tolerance. Minimal-model approach. Diabetes 1989, 38(12):1512-1527.

21. Matsuda M, DeFronzo RA: Insulin sensitivity indices obtained from oral glucose tolerance testing: comparison with the euglycemic insulin clamp. Diabetes Care 1999, 22(9):1462-1470.

22. Matsuda M: Measuring and estimating insulin resistance in clinical and research settings. Nutr Metab Cardiovasc Dis 2010, 20(2):79-86.

23. Ascaso JF, Pardo S, Real JT, Lorente Rl, Priego A, Carmena R: Diagnosing insulin resistance by simple quantitative methods in subjects with normal glucose metabolism. Diabetes Care 2003, 26(12):3320-3325.

24. Lorenzo C, Haffner SM, Stancakova A, Laakso M: Relation of direct and surrogate measures of insulin resistance to cardiovascular risk factors in nondiabetic finnish offspring of type 2 diabetic individuals. J Clin Endocrinol Metab 2011, 95(11):5082-5090.

25. Carnevale Schianca GP, Sainaghi PP, Castello L, Rapetti R, Limoncini AM, Bartoli E: Comparison between HOMA-IR and ISI-gly in detecting subjects with the metabolic syndrome. Diabetes Metab Res Rev 2006, 22(2):111-117.

26. Kanauchi $M$, Kanauchi $K$, Inoue $T$, Kimura $K$, Saito $Y$ : Surrogate markers of insulin resistance in assessing individuals with new categories "prehypertension" and "prediabetes". Clin Chem Lab Med 2007, 45(1):35-39.

27. Ferrannini E, Balkau B: Insulin: in search of a syndrome. Diabet Med 2002, 19(9):724-729.

28. Mason C, Foster-Schubert KE, Imayama I, Kong A, Xiao L, Bain C, Campbell KL, Wang CY, Duggan CR, Ulrich CM, et al: Dietary weight loss and exercise effects on insulin resistance in postmenopausal women. American journal of preventive medicine 2011, 41(4):366-375.

29. Borai A, Livingstone C, Shafi S, Zarif H, Ferns G: Insulin sensitivity (Si) assessment in lean and overweight subjects using two different protocols and updated software. Scand I Clin Lab Invest 2010, 70(2):98-103.

30. Abdul-Ghani MA, Matsuda M, Balas B, DeFronzo RA: Muscle and live insulin resistance indexes derived from the oral glucose tolerance test. Diabetes Care 2007, 30(1):89-94

31. Balion CM, Raina PS, Gerstein HC, Santaguida PL, Morrison KM, Booker L, Hunt DL: Reproducibility of impaired glucose tolerance (IGT) and impaired fasting glucose (IFG) classification: a systematic review. Clin Chem Lab Med 2007, 45(9):1180-1185.

32. Atabek ME, Pirgon O: Assessment of insulin sensitivity from measurements in fasting state and during an oral glucose tolerance test in obese children. J Pediatr Endocrinol Metab 2007, 20(2):187-195.

33. Raynaud E, Perez-Martin A, Brun JF, Benhaddad AA, Mercier J: Revised concept for the estimation of insulin sensitivity from a single sample. Diabetes Care 1999, 22(6):1003-1004.

34. Hermans MP, Levy JC, Morris RJ, Turner RC: Comparison of insulin sensitivity tests across a range of glucose tolerance from normal to diabetes. Diabetologia 1999, 42(6):678-687.

35. Disse E, Bastard JP, Bonnet F, Maitrepierre C, Peyrat J, Louche-Pelissier C, Laville M: A lipid-parameter-based index for estimating insulin sensitivity and identifying insulin resistance in a healthy population. Diabetes Metab 2008, 34(5):457-463.

36. Matthews DR, Hosker JP, Rudenski AS, Naylor BA, Treacher DF, Turner RC: Homeostasis model assessment: insulin resistance and beta-cell function from fasting plasma glucose and insulin concentrations in man. Diabetologia 1985, 28(7):412-419.

37. Wallace TM, Levy JC, Matthews DR: Use and abuse of HOMA modeling. Diabetes Care 2004, 27(6):1487-1495.

38. Perseghin G, Caumo A, Caloni M, Testolin G, Luzi L: Incorporation of the fasting plasma FFA concentration into QUICKI improves its association with insulin sensitivity in nonobese individuals. J Clin Endocrinol Metab 2001, 86(10):4776-4781.

39. Ijzerman RG, Stehouwer CD, Serne EH, Voordouw JJ, Smulders YM, Delemarre-van de Waal HA, van Weissenbruch MM: Incorporation of the fasting free fatty acid concentration into quantitative insulin sensitivity check index improves its association with insulin sensitivity in adults, but not in children. Eur J Endocrinol 2009, 160(1):59-64.

40. Li X, Zhou ZG, Qi HY, Chen XY, Huang G: [Replacement of insulin by fasting C-peptide in modified homeostasis model assessment to evaluate insulin resistance and islet beta cell function]. Zhong Nan Da Xue Xue Bao Yi Xue Ban 2004, 29(4):419-423.

41. Quon MJ: Limitations of the fasting glucose to insulin ratio as an index of insulin sensitivity. J Clin Endocrinol Metab 2001, 86(10):4615-4617.

42. Albareda M, Rodriguez-Espinosa J, Murugo M, de Leiva A, Corcoy R: Assessment of insulin sensitivity and beta-cell function from measurements in the fasting state and during an oral glucose tolerance test. Diabetologia 2000, 43(12):1507-1511.

43. Bonora E, Targher G, Alberiche M, Bonadonna RC, Saggiani F, Zenere MB, Monauni T, Muggeo M: Homeostasis model assessment closely mirrors the glucose clamp technique in the assessment of insulin sensitivity: studies in subjects with various degrees of glucose tolerance and insulin sensitivity. Diabetes Care 2000, 23(1):57-63.

44. Emoto M, Nishizawa Y, Maekawa K, Hiura Y, Kanda H, Kawagishi T, Shoji T, Okuno Y, Morii H: Homeostasis model assessment as a clinical index of insulin resistance in type 2 diabetic patients treated with sulfonylureas. Diabetes Care 1999, 22(5):818-822

45. Fukushima M, Taniguchi A, Sakai M, Doi K, Nagata I, Nagasaka S, Tokuyama K, Nakai Y: Assessment of insulin sensitivity from a single sample. Diabetes Care 2000, 23(9):1434-1435.

46. Katz A, Nambi SS, Mather K, Baron AD, Follmann DA, Sullivan G, Quon MJ: Quantitative insulin sensitivity check index: a simple, accurate method for assessing insulin sensitivity in humans. J Clin Endocrinol Metab 2000, 85(7):2402-2410

47. Yokoyama H, Emoto M, Fujiwara S, Motoyama K, Morioka T, Komatsu M, Tahara H, Koyama H, Shoji T, Inaba M, et al: Quantitative insulin sensitivity check index and the reciprocal index of homeostasis model assessment are useful indexes of insulin resistance in type 2 diabetic patients with wide range of fasting plasma glucose. I Clin Endocrinol Metab 2004, 89(3):1481-1484

48. Borai A, Livingstone C, Farzal A, Kholeif M, Wang T, Ferns G: Reproducibility of HOMA and QUICKI among individuals with variable glucose tolerance. Diabetes Metab 2010, 36(3):247-249.

49. Jayagopal V, Kilpatrick ES, Jennings PE, Hepburn DA, Atkin SL: Biological variation of homeostasis model assessment-derived insulin resistance in type 2 diabetes. Diabetes Care 2002, 25(11):2022-2025.

50. Liang L, Fu JF, Zou CC, Hong F, Wang CL, Wang XM: [Metformin hydrochloride ameliorates adiponectin levels and insulin sensitivity in adolescents with metabolic syndrome]. Zhonghua Er Ke Za Zhi 2006, 44(2):118-121.

51. Borai A, Callum L, Hawazen Z, Shweta M, Mona K, Mohammed A, Hanin A Gordon F: A comparative study of insulin resistance for Saudi and Caucasian subjects across a range of glycaemic categories. Diabetes and Metabolic Syndrome: Clinical Research and Reviews 2009, 3:204-210.

52. Manley SE, Stratton IM, Clark PM, Luzio SD: Comparison of 11 human insulin assays: implications for clinical investigation and research. Clin Chem 2007, 53(5):922-932.

53. Manley SE, Luzio SD, Stratton IM, Wallace TM, Clark PM: Preanalytical, analytical, and computational factors affect homeostasis model assessment estimates. Diabetes Care 2008, 31(9):1877-1883.

54. Esteghamati A, Ashraf H, Esteghamati AR, Meysamie A, Khalilzadeh O, Nakhjavani M, Abbasi M: Optimal threshold of homeostasis model assessment for insulin resistance in an Iranian population: the implication of metabolic syndrome to detect insulin resistance. Diabetes Res Clin Pract 2009, 84(3):279-287.

55. Merino-Ibarra E, Cenarro A, Martin P, Garcia-Otin AL, Goicoechea J, Guallar A, Calvo L, Civeira F: [Sensitivity and specificity of metabolic syndrome criteria for insulin resistance diagnosis in Spanish population]. Medicina clinica 2007, 128(5):168-171.

56. Ferrara CM, Goldberg AP: Limited value of the homeostasis model assessment to predict insulin resistance in older men with impaired glucose tolerance. Diabetes Care 2001, 24(2):245-249. 
57. Katsuki A, Sumida Y, Urakawa H, Gabazza EC, Murashima S, Morioka K, Kitagawa N, Tanaka T, Araki-Sasaki R, Hori Y, et al: Neither homeostasis model assessment nor quantitative insulin sensitivity check index can predict insulin resistance in elderly patients with poorly controlled type 2 diabetes mellitus. J Clin Endocrinol Metab 2002, 87(11):5332-5335.

58. Legro RS, Finegood D, Dunaif A: A fasting glucose to insulin ratio is a useful measure of insulin sensitivity in women with polycystic ovary syndrome. J Clin Endocrinol Metab 1998, 83(8):2694-2698.

59. Hoffman RP: Indices of insulin action calculated from fasting glucose and insulin reflect hepatic, not peripheral, insulin sensitivity in AfricanAmerican and Caucasian adolescents. Pediatric diabetes 2008, 9(3 Pt 2):57-61.

60. Kalme T, Seppala M, Qiao Q, Koistinen R, Nissinen A, Harrela M, Loukovaara M, Leinonen P, Tuomilehto J: Sex hormone-binding globulin and insulin-like growth factor-binding protein-1 as indicators of metabolic syndrome, cardiovascular risk, and mortality in elderly men. J Clin Endocrinol Metab 2005, 90(3):1550-1556.

61. Heald AH, Kaushal K, Siddals KW, Rudenski AS, Anderson SG, Gibson JM: Insulin-like growth factor binding protein-2 (IGFBP-2) is a marker for the metabolic syndrome. Exp Clin Endocrinol Diabetes 2006, 114(7):371-376.

62. Kupelian V, Page ST, Araujo AB, Travison TG, Bremner WJ, McKinlay JB: Low sex hormone-binding globulin, total testosterone, and symptomatic androgen deficiency are associated with development of the metabolic syndrome in nonobese men. J Clin Endocrinol Metab 2006, 91(3):843-850.

63. Roa Barrios M, Arata-Bellabarba G, Valeri L, Velazquez-Maldonado E: [Relationship between the triglyceride/high-density lipoproteincholesterol ratio, insulin resistance index and cardiometabolic risk factors in women with polycystic ovary syndrome]. Endocrinol Nutr 2009, 56(2):59-65.

64. Oda N, Imamura S, Fujita T, Uchida Y, Inagaki K, Kakizawa H, Hayakawa N, Suzuki A, Takeda J, Horikawa $Y$, et al: The ratio of leptin to adiponectin can be used as an index of insulin resistance. Metabolism 2008, 57(2):268-273.

65. Finucane FM, Luan J, Wareham NJ, Sharp SJ, O'Rahilly S, Balkau B, Flyvbjerg A, Walker M, Hojlund K, Nolan JJ, et al: Correlation of the leptin: adiponectin ratio with measures of insulin resistance in non-diabetic individuals. Diabetologia 2009, 52(11):2345-2349.

66. Hoffman RP: Metabolic syndrome racial differences in adolescents. Curr Diabetes Rev 2009, 5(4):259-265.

67. Jayagopal V, Kilpatrick ES, Jennings PE, Holding S, Hepburn DA, Atkin SL: The biological variation of sex hormone-binding globulin in type 2 diabetes: implications for sex hormone-binding globulin as a surrogate marker of insulin resistance. Diabetes Care 2004, 27(1):278-280.

68. Borai A, Livingstone C, Mehta S, Zarif H, Abdelaal F, Ferns G: Biological variation in fasting serum insulin-like growth factor binding protein-1 (IGFBP-1) among individuals with a varying glucose tolerance. Clin Biochem 2009, 42(12):1270-1274.

69. Ricos C, Iglesias N, Garcia-Lario JV, Simon M, Cava F, Hernandez A, Perich C, Minchinela J, Alvarez V, Domenech MV, et al: Within-subject biological variation in disease: collated data and clinical consequences. Ann Clin Biochem 2007, 44(Pt 4):343-352.

70. Hanson RL, Pratley RE, Bogardus C, Narayan KM, Roumain JM, Imperatore G, Fagot-Campagna A, Pettitt DJ, Bennett PH, Knowler WC: Evaluation of simple indices of insulin sensitivity and insulin secretion for use in epidemiologic studies. Am J Epidemiol 2000, 151(2):190-198.

71. Kim SM, Cho KH, Park HS: Relationship between Plasma Adiponectin Levels and the Metabolic Syndrome among Korean People. Endocr J 2006, 53(2):247-254.

72. Pigeon E, Riou ME, St-Onge J, Couillard E, Tremblay A, Marette A, Weisnagel SJ, Joanisse DR: Validation of a simple index (SlisOGTT) of insulin sensitivity in a population of sedentary men. Diabetes Metab 2009, 35(5):398-403.

73. Sarafidis PA, Lasaridis AN, Nilsson PM, Pikilidou MI, Stafilas PC, Kanaki A, Kazakos K, Yovos J, Bakris GL: Validity and reproducibility of HOMA-IR, 1/ HOMA-IR, QUICKI and McAuley's indices in patients with hypertension and type II diabetes. J Hum Hypertens 2007, 21(9):709-716.

74. Belfiore F, lannello S, Volpicelli G: Insulin sensitivity indices calculated from basal and OGT-induced insulin, glucose, and FFA levels. Mol Genet Metab 1998, 63(2):134-141.

\section{Pre-publication history}

The pre-publication history for this paper can be accessed here: http://www.biomedcentral.com/1471-2288/11/158/prepub

doi:10.1186/1471-2288-11-158

Cite this article as: Borai et al: Selection of the appropriate method for the assessment of insulin resistance. BMC Medical Research Methodology 2011 11:158.

\section{Submit your next manuscript to BioMed Central and take full advantage of:}

- Convenient online submission

- Thorough peer review

- No space constraints or color figure charges

- Immediate publication on acceptance

- Inclusion in PubMed, CAS, Scopus and Google Scholar

- Research which is freely available for redistribution 